\title{
Bir Devlet Hastanesi Acil Servisinden Göğüs Hastalıkları Servisine İstenen Konsültasyonların Değerlendirilmesi
}

\section{Evaluation of Consultations Requested from Emergency Departments to Chest Diseases Department}

iD Begüm Üzer', iD Fatih Üzer², iD Sait Karakurt ${ }^{3}$

${ }^{1}$ Kastamonu Devlet Hastanesi Acil Servis, Kastamonu, Türkiye

${ }^{2}$ Kastamonu Devlet Hastanesi Göğüs Hastalıkları, Kastamonu, Türkiye

${ }^{3}$ Marmara Üniversitesi Tıp Fakültesi Göğüs Hastalıkları Anabilim Dalı, İstanbul, Türkiye

$\ddot{\mathrm{O} z}$

Amaç: Bu çalışma, bir devlet hastanesi acil servisinden göğüs hastalıkları bölümüne istenen konsültasyonların genel klinik özelliklerini ve konsültasyon istenme nedenlerini ortaya koymak amaciyla tasarland.

Gereç ve yöntem: Çalışma restropsektif bir çalışmadır. Çalışmaya 1 Ocak 2018-31 Aralık 2018 tarihleri arasında Kastamonu Devlet Hastanesi Acil Servisi'ne başvuran ve gögüs hastalıkları konsültasyonu(GHK) istenen hastalar dahil edildi. Hastaların sosyodemografik verileri, başvuru şikayetleri, hastaneye geliş şekilleri, evde cihaz kullanımı durumları, konsültan hekimin konsültasyona cevap verme süresi, konsültasyon ön tanısı, konsültasyon sonrası aldığı son tanı, radyolojik bulguları veri toplama formuna kaydedildi. Kendi isteğiyle hastaneden ayrılan, dosya bilgileri eksik olan ve konsültasyon istenmesine rağmen herhangi bir nedenle göğüs hastalıkları uzmanı tarafından değerlendirilmeyen hastalar çalışma dışı bırakıldı.

Bulgular: Çalışmaya ortalama yaşı 72,8 14,4 olan, 280(\%53,9) erkek, 239(\%46,1) kadın hasta çalışmaya dahil edildi. En sık eşlik eden hastalıkları kardiyovasküler hastalıklar iken, en sık başvuru nedeni nefes darlığı idi. En sık pnömoni, kronik obstruktif akciğer hastalığı alevlenmesi ve pulmoner emboli nedeniyle GHK istenmişti. Göğüs hastalıkları uzmanlarının acilden istenen konsültasyonları yanıtlama süresi 93,8 (1-837) dakika olarak tespit edildi. Akciğer grafisinde en sık saptanan radyolojik anormallik infiltrasyondu. Acil servisten istenen konsültasyonların \%20(104) terminal dönem hastalardan oluşmaktaydı

Sonuç: Acil servislerden istenen GHK önemli bir kısmının ileri yaşta, bakıma muhtaç hastalardan oluştuğu gözlemlendi. En sık hastaneye yatış nedeninin pnömoni olduğu sonucuna varıldı.

Anahtar sözcükler: Acil servis, Göğüs Hastalıkları, Konsültasyon

Summary

Aim: This study was designed to evaluate the consultations that were requested from a public hospital's emergency department to the department of chest diseases (DCD).

Methods: Patients who were admitted to the state hospital emergency department and who were consulted to DCD were included in the study. Clinical features of patients were recorded in the data collection form. Patients who voluntarily left the hospitals, who has missing file data and who were not evaluated by the chest diseases specialist for any reason despite consultation were requested, were excluded from the study.

Results: $280(53.9 \%)$ male and 239(46.1\%) female patients with a mean age of $72.8 \pm 14.4$ were included in the study. The most common concomitant disease were cardiovascular diseases, and the most common complaint for presentation was dyspnea. Chest diseases consultations was requested most frequently due to pneumonia and exacerbation of chronic obstructive lung disease. The response time of pulmonologists for urgent consultations was 93.8 $\pm 127.3(1-837)$ minutes. $20 \%(104)$ of the consultations requested from the emergency department consisted of patients in terminal period of a disease.

Conclusion: It was observed that a significant part of the patients were at advanced age and in need of care. It was concluded that the most common reason for hospitalization was pneumonia.

Keywords: Emergency room, Chest Diseases, Consultation

Yazışma Adresi: Fatih Üzer, Kastamonu Devlet Hastanesi, Göğüs Hastalıkları, Kastamonu, Türkiye

E-Posta: uzerfatih@gmail.com

Alınma tarihi: 23.07.2020 / Kabul tarihi: 05.02.2021 / Yayımlanma tarihi: 20.09.2021

Acil servis ve göğüs hastalıkları - Üzer ve ark. 


\section{Giriş}

Acil servisler her türlü acil hastanın bakıldığ 1,7 gün 24 saat kesintisiz hizmet sunan ve hastanelerin vitrini olarak kabul edilen önemli birimlerinden biridir. Acil servislere başvuran hastaların çeşitliliği fazladır. Acil servis hastalarının, genellikle hemen müdahale gerektiren, çeşitli medikal, cerrahi ve davranışsal sorunları vardır. $\mathrm{Bu}$ hastaların tanı ve tedavisinde disiplinler arası yaklaşım gerekir. Bir olguya bütüncül yaklaşabilmek için, birden fazla tıp alanının birlikte çalışması da kaçınılmazdır.

Konsültasyon bir hastanın takip ve tedavisi konusunda ilgili hekim ya da hekimlerin fikrini alma ve öneriler doğrultusunda hastanın izlemine yön verme anlamına gelir. Hastanın tedavi başarısı veya başarısızlı̆̆ hastayı izleyen primer hekime aittir. Bu nedenle hekim, hastasını konusunda en güvendiği doktora danışmak zorundadır. Konsültasyona çağrılan hekimin, hasta hakkındaki bilgiyi hastayı izleyen doktora eksiksiz biçimde sözlü ve yazılı olarak aktarması ve hasta yararına olan en gerekli işlemi öncelikle uygulaması gerekir Etik açıdan konsültan hekimin önerilerine tümü ile uymak gerekir Tıbbı Deotoloji Tüzüğü madde 28'e göre hekimler arasında aykırılık doğar ve hasta konsültasyona gelen hekimin düşüncelerini yeğlerse hastanın müdavi hekiminin o hastayı bırakma hakkı bulunmaktadır (1) . Konsültasyon sonucunda hastayı takip eden primer hekim, kendi konusu dışındaki bir hastayı, ilgili meslektaşına refere edebilir. Bu durumda, tedavi sorumluluğu konsültan hekime geçer $(2,3)$.

Göğüs hastalıkları konsültasyonu (GHK) acil servis tarafından en sık istenen konsültasyonlardan biridir (3). GHK, genellikle hastaların solunum sistemiyle ilgili radyolojik, laboratuvar (hipoksemi, hiperkapni, oksijen desaturasyonu vb.) ve fizik muayene bulgularına göre anormallik saptanması nedeniyle istenmektedir (4-6). Bu çalışma, bir devlet hastanesi acil servisinden son bir yılda göğüs hastalıkları bölümüne istenen konsültasyonların genel klinik özelliklerini, konsültasyon istenme nedenlerini, konsültasyon sonucunda yapılan incelemeler ve varılan sonuçları ortaya koymak amacıyla tasarlandı.

\section{Gereç ve Yöntem}

Kastamonu Devlet Hastanesi 400 yataklı bir hastane olup 35 yataklı göğüs hastalıkları servisine sahiptir. Hastanede 5 göğüs hastalıkları polikliniği bulunmasına rağmen çalışmanın yapıldığı dönemde göğüs hastalıkları poliklinik sayısı 0-3 arasında değişmekteydi. 1-31 Mart 2018 tarihleri arasında göğüs hastalıkları uzmanı bulunmamaktaydı. Çalışma için 1 Ocak 2018-31 Aralık 2018 tarihleri arasında Kastamonu Devlet Hastanesi Acil Servisi'ne başvuran ve ilgili hekim tarafindan göğüs hastalıkları konsültasyonu istenen hastalar retrospektif olarak tarandı. Hastaların sosyodemografik verileri, başvuru şikayetleri, hastaneye geliş şekilleri (ambulans, kendi imkanları), temel ihtiyaçlarını kendi başına karşılayıp karşılayamadıkları, evde cihaz kullanımı durumları (nebulizatör, noninvaziv ventilasyon cihazı, oksijen konsantrantörü), konsültan hekimin konsültasyona cevap verme süresi, hastanın konsülte edilme nedeni olan ön tanısı, konsültasyon sonrası aldığı son tanı ve akıbeti, radyolojik bulguları, yattı ise yattığ1 süre veri toplama formuna kaydedildi. Hastaneye başvurduğu dönemde çekilen akciğer grafileri ve toraks bilgisayarlı tomografileri göğüs hastalıkları uzmanı tarafından değerlendirildi. $\mathrm{Bu}$ tarihlerde mükerrer başvurusu olan hastaların ilk başvuruları alındı. Kendi isteğiyle hastaneden ayrılan, dosya bilgileri eksik olan ve konsültasyon istenmesine rağmen herhangi bir nedenle göğüs hastalıkları uzmanı tarafından değerlendirilmeyen hastalar çalışma dışı bırakıldı.

Çalışmanın etik kurul onayı; Karabük Üniversitesi Girişimsel Olmayan Klinik Araştırmalar Kurulu tarafından 19.04.2019 tarihinde $5 / 5$ nolu karar ile alınmıştır.

Tanımlayıcı istatistikler ortalama, standart sapma, ortanca, frekans ve yüzde değerleri ile sunulmuştur. Grupların cinsiyet dağılımlarının farklılıklarının incelenmesi amacı ile ki-kare testi yapılmıştır. Farklı olan grupların tespit edilmesi amacı ile Bonferroni yöntemi uygulanmıştır. Cinsiyete göre yaş ve yatış günü açısından farklılı̆̆ın incelenmesi için Mann-Whitney U testi kullanılmıştır. Çalışmada 0,05'ten küçük p değerleri istatistiksel olarak anlamlı kabul edilmiştir. Analizler SPSS 22.0 (SPSS/IBM, Chicago, IL, USA) paket programı ile yapılmıştır.

\section{Bulgular}

Çalışmanın yapıldı̆̆ 1 tarihte Kastamonu Devlet Hastanesi yetişkin acil servisine 159132 hastanın başvurduğu öğrenildi. Bu hastaların $957(\% 0,6)$ 'sinden GHK yapıldığı öğrenildi. Çalışmaya dosya verileri uygun olan ve göğüs hastalıkları uzmanı tarafından değerlendirilmiş olan 519 hasta dahil edildi. 438 konsültasyon çeşitli sebeplerden (dosyada yeterli bilgi olmayan hastalar (60), mükerrer başvuru (324), göğüs hastalıkları uzmanı tarafından değerlendirilmeden hastaneden ayrılma (54)) ötürü çalışmaya dahil edilmedi.

Ortalama yaşı 72,8 $\pm 14,4$ olan, $280(\% 53,9)$ erkek, $239(\% 46,1)$ kadın hasta çalışmaya dahil edildi. Acil servise başvuru imkanına ulaşılan 337 hastanın \%53,1 (179)'inin ambulans ile hastaneye getirildiği, geri kalanının ise kendi imkanları ile hastaneye başvurduğu öğrenildi.

Olguların \%55,7 (289)'s1 dispne, \%21,2 (110)'si genel durum bozukluğu, \%8,3 (43)'si öksürük ve/veya balgam, \%2,7 (14)'si hemoptizi ve \%12,1 (63)'i pulmoner dışı semptomlarla hastaneye başvurmuştu. Hastaların yaklaşık üçte biri (170) temel ihtiyaçları için başkasının yardımına ihtiyaç duyuyordu. En sık komorbid hastalıklar sırasıyla; kardiyovasküler hastalıklar $(\mathrm{n}=309, \% 59,5)$, solunum sistemi hastalıkları $(\mathrm{n}=293, \% 56,4)$ ve endokrinolojik hastalıklar $(\mathrm{n}=121, \% 23,3)$ iken herhangi bir komorbid hastalığı olmayanlar tüm hastaların \%10,1 (57)'i idi. 158 hastanın ise eşlik eden en az 3 hastalığı vardı. Çalışmamızda sigara içme öyküsüne ulaşılan 160 hastanın \%51,9 (83)'nün hiç sigara içmediği, \%33,8 (54)'nün önceden sigara içtiği, 11,2 (18)'nin pasif içici olduğu ve \%3,1 (5) sigara içmeye devam ettiği tespit edildi. Hastaların \%22,9 (119)'unun nebulizatör cihazı, \%11,7 (61)'sinin oksijen konsantratörü ve \%3,6 (19)'sının noninvaziv mekanik ventilasyon (NIMV) kullandığı saptandı (Tablo 1). NiMV kullanan hastaların cihaz uyumlarının iyi olmadığı, ancak sıkışık hissettiği zaman kullandığı öğrenildi.

Hastaların vital bulgular1; sistolik tansiyon $125,7 \pm 43,7 \mathrm{mmHg}$,

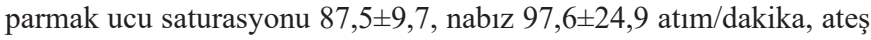
$37,3 \pm 0,9$ derece iken solunum sistemi muayenesinde \%31 (161)'inde ral, \%27(140)'sinde ronküs, \%23,9 (124)'ünde solunum seslerinde azalma tespit edildi (Tablo 2).

Gögüs hastalıkları uzmanlarının acilden istenen konsültasyonları yanttlama süresi 93,8 (1-837) dakika olarak tespit edildi. En sik saptanan radyolojik bulgular akciğer grafisinde; infiltrasyonkonsolidasyon $(\% 35,5)$, normal bulgular $(\% 21,1)$, plevral efüzyon 
$(\% 20,1)$ iken bilgisayarlı toraks tomografisinde infiltrasyonkonsolidasyon $(\% 39,4)$, plevral efüzyon $(\% 18,8)$, vasküler patolojiler $(\% 9,2)$, sekel bulgular $(\% 6,6)$ ve diğer bulgular (intertisyel bulgular, kaviter lezyon, nodül vs) $(\% 15,9)$ idi.

Tablo 1.Hastaların genel özellikleri

\begin{tabular}{|c|c|c|}
\hline & Özellik & $\mathrm{n}(\%)$ \\
\hline \multirow[t]{2}{*}{ Cinsiyet } & Kadın & $239(46,1)$ \\
\hline & Erkek & $280(53,9)$ \\
\hline \multirow[t]{2}{*}{ Acil servise başvuru } & Ambulans & $179(53,1)$ \\
\hline & Kendi imkanları & $158(46,9)$ \\
\hline \multirow[t]{5}{*}{ Başvuru nedeni } & Dispne & $289(55,7)$ \\
\hline & Genel durum bozukluğu & $110(21,2)$ \\
\hline & Öksürük /balgam & $43(2,7)$ \\
\hline & Hemoptizi & $14(2,7)$ \\
\hline & Pulmoner dışı semptomlar & $63(12,1)$ \\
\hline \multirow[t]{3}{*}{ Komorbidite } & Kardiyovasküler hastalıklar & $309(59,5)$ \\
\hline & Solunum sistemi hastalıkları & $293(56,4)$ \\
\hline & Endokrinolojik hastalıklar & $121(23,3)$ \\
\hline \multirow[t]{3}{*}{ Cihaz kullanımı } & Nebulizatör cihazı & $119(22,9)$ \\
\hline & Oksijen konsantratörü & $61(11,7)$ \\
\hline & Noninvaziv ventilasyon cihazı & $19(3,6)$ \\
\hline \multirow[t]{4}{*}{ Konsültasyon sonucu } & Yatarak tedavi & $254(48,9)$ \\
\hline & Ayaktan tedavi & $150(28,9)$ \\
\hline & Yoğun bakım gereksinimi & $78(15)$ \\
\hline & Daha kapsamlı hastaneye sevk & $17(3,8)$ \\
\hline
\end{tabular}

Tablo 2. Vital bulgulara ve solunum sistemi muayenesine göre hastaların değerlendirilmesi

\begin{tabular}{ll}
\hline Bulgu & ortalama \pm standart sapma \\
\hline Kan basıncı (sistolik) (mmHg) & $125,7 \pm 43,7$ \\
Parmak ucu saturasyonu & $87,5 \pm 9,7$ \\
Kalp atım hızı (dakika) & $97,6 \pm 24,9$ \\
Ateş (derece) & $37,3 \pm 0,9$ \\
\hline Oskültasyon bulguları & $\mathrm{n}(\%)$ \\
\hline Ral & $161(\% 31)$ \\
Ronküs & $140(\% 27)$ \\
Solunum seslerinde azalma & $124(\% 23,9)$ \\
\hline
\end{tabular}

Tablo 3.Ön tanılar ve son tanılara göre hastaların sınıflandırılması

\begin{tabular}{lll}
\hline Sıklık sırası & Ön tanı (n) (\%) & Son tanı (n) $(\%)$ \\
\hline 1. & Pnömoni $(261)(\% 50,2)$ & Pnömoni (198) $(\% 38,1)$ \\
2. & KOAH alevlenmesi $(101)(\% 19,4)$ & KOAH alevlenmesi $(93)(\% 17,9)$ \\
3. & Pulmoner Emboli $(68)(\% 13,1)$ & Pulmoner dışı nedenler (88) (\%17) \\
4. & Diğer (48) $(\% 9,2)$ & Astım alevlenmesi $(72)(\% 13,8)$ \\
5. & Astım alevlenmesi $(41)(\% 7,8)$ & Pulmoner Emboli $(50)(\% 9,6)$
\end{tabular}

KOAH: kronik obstrüktif akciğer hastalı̆ğ

Acil servis ve göğüs hastalıkları - Üzer ve ark.
Konsültasyonların \%50,2'ü (261) pnömoni \%19,4'si (101) kronik obstrüktif akciğer hastalığı (KOAH) alevlenmesi ve \%13,1'i (68) pulmoner Emboli (PE) ön tanısı ile istenmişken, hastaların aldığ son tan1lar \%38,1 (198) pnömoni, \%17,9 (93) KOAH alevlenmesi, $\% 13,8$ (72) astım atak, \%9,6 (50) PE ve \%17 (88) pulmoner dış1 nedenler olarak tespit edildi. Son tanılardan en sık pulmoner dışı neden kalp yetmezliğine bağlı olan solunum yetersizliği idi (Tablo 3 ). $\mathrm{Bu}$ hastalara acil serviste non-invaziv mekanik ventilayon uyguland. PE'nin en sık nedeninin immbolizasyon ( $n=18, \% 36)$ olduğu görüldü.

Konsültasyon istenen hastaların \%48,9 (254)'u servislerde yatarak tedavi gördüğü, \%28,9 (150)'u ayaktan tedavi almak üzere acil servisten taburcu olduğu, \%15 (78)'i yoğun bakım ünitesine yatarak tedavi gördüğ̈̈ ve \%3,8 (17)'i daha kapsamlı bir hastaneye acil servisten sevk olduğu tespit edildi. Göğüs hastalıkları servisine yatarak tedavi gören hastaların ortalama hastanede yatma süresi $10,9 \pm 14,4$ gün olduğu, hastaların \%40,9 (104)'u şifa ile, \%44,9 (114)'u haliyle taburcu olduğu, \%3,9 (10)'unun yoğun bakım ihtiyacı olduğu, \%5,5 (14)' $i$ ise kendi isteğiyle göğüs hastalıkları servisinden ayrıldığ 1 saptandı. Acil servisten yataklı servise yatan hastaların mortalite oran1 \%4,7 (12) idi. Acil servisten istenen konsültasyonların \%20 (104) terminal dönem hastalardan oluşmaktaydı. Konsultasyonların mevsimlere göre dağılımı incelendiğinde; \%36,2 (188)'nin sonbaharda, \%27 (140)'nin kışın, \%14,5 (75)'inin ilkbaharda, \%22,3 (116)'ünün yazın istendiği tespit edildi. Hasta sosyodemografik ve klinik özelliklerinin mevsimsel dağılımı tablo 4’te verildi.

Tablo 4. Hastaların sosyodemografik özelliklerinin ve son tanılarına göre klinik özelliklerinin mevsimlere göre dağılımı

\begin{tabular}{|c|c|c|c|c|c|}
\hline & Sonbahar & $\mathrm{K}_{1}$ ş & İlkbahar & Yaz & Total \\
\hline İstenen konsultasyon $\mathrm{n}(\%)$ & $293(30,6)$ & $275(28,7)$ & $\begin{array}{l}178 \\
(18,6)\end{array}$ & $211(22,1)$ & $957(100)$ \\
\hline Çalışmaya dahil edilen $\mathrm{n}(\%)$ & $188(36,2)$ & $140(27)$ & $75(14,5)$ & $116(22,3)$ & $519(100)$ \\
\hline Kadin n (\%) & $73(30,5)$ & $80(33,5)$ & $35(14,6)$ & $51(21,4)$ & $239(100)$ \\
\hline Erkek n (\%) & $115(41,8)$ & $60(21,4)$ & $40(14,3)$ & $65(22,5)$ & $280(100)$ \\
\hline Yaş (yil) & $71,5 \pm 15,2$ & $71,9 \pm 14,0$ & $73,4 \pm 13,3$ & $73,7 \pm 14,2$ & $72,8 \pm 14,4$ \\
\hline KOAH n (\%) & $40(43)$ & $26(28)$ & $12(12,9)$ & $15(16,1)$ & $93(100)$ \\
\hline Pnömoni n (\%) & $74(37,4)$ & $62(31,3)$ & $27(13,6)$ & $35(17,7)$ & $198(100)$ \\
\hline Pulmoner Emboli n (\%) & $17(34)$ & $15(30)$ & $4(8)$ & $14(28)$ & $50(100)$ \\
\hline Astım n (\%) & $21(29,2)$ & $17(23,6)$ & $14(19,4)$ & $20(27,8)$ & $72(100)$ \\
\hline $\begin{array}{l}\text { Mortalite (servis yatışı } \\
\text { sonrası) } \mathrm{n}(\%)\end{array}$ & $2(16,7)$ & $6(50)$ & - & $4(33,3)$ & $12(100)$ \\
\hline
\end{tabular}

\section{Tartışma}

Ülkemizde GHK'yı değerlendiren birçok çalışma yapılmıştır. Bu çalışmada ülkemizde yapılan diğer çalışmalardan farklı olarak ikinci basamak bir devlet hastanesinde sadece acil servisten istenen konsültasyonlar değerlendirilmiştir. Diğer çalışmalar ise yatarak 
tedavi gören ya da perioperatif hazırlık yapılan hastalarda yapılmıştır (4,6-9). Çalışmamızda acil servisten istenen konsültasyonların genellikle bakıma muhtaç, yaşlı hastalardan oluştuğu, en s1k konsültasyon istenme sebebinin pnömoni ve en sık başvuru nedenin ise dispne olduğu tespit edildi. Ülkemizde yapılmış diğer çalışmalarda, Annakkaya ve ark.'nın (7), Öztürk ve ark.'nın (10), Arslan ve ark.'nın (4) çalışmalarında en sık cerrahi branşlardan konsültasyon istendiği sonucuna ulaşılmıştır. Bu çalışmaların bir kısmında acil servis dahili branş olarak kabul edilirken, bir kısmında cerrahi branş olarak kabul edilmiştir. Çalışmamızda olduğu gibi spesifik olarak acil servis konsültasyonlarını değerlendiren çalışmalara ulaşılamadı.

Çalışmaya alınan hastalar cinsiyetlerine göre değerlendirildiğinde; 280 erkek $(\% 53,9)$ ve 239 kadın $(\% 46,1)$ olmak üzere konsültasyon istenen erkek hastaların bir miktar daha fazla olduğu gözlendi. Ülkemizde yatarak tedavi gören hastalarda ve perioperatif hazırlık için istenen konsültasyonların değerlendirildiği diğer çalışmalarda da erkeklerden daha sık GHK istendiği belirtilmiştir $(7,8,10)$. Türkiye'den yapılan en fazla hasta sayısına sahip çalışmada; Çakmak ve arkadaşları 5000'den fazla GHK'yı incelediği çalışmasında \%58 oranında erkek hastalara daha fazla konsültasyon istendiğini saptamıştır (9). Toplumda sık görülen akciğer kanseri, KOAH gibi rahatsızlıklar sigara içimiyle ilişkilidir. Erkeklerin kadınlardan daha fazla sigara içici olması konsültasyonların neden erkek hastalardan daha çok istendiğinin bir açıklaması olabilir.

Çalışmamızda en çok dispne nedeniyle GHK istenmişti. Arslan ve arkadaşlarının (4) çalışmasında çalışmamızda benzer olarak en sık konsültasyon istenme sebebi dispne iken, Öztürk ve arkadaşlarının (10) çalışmasında en sık konsültasyon istenme sebebi öksürüktür. Bunun yanında bazı çalışmalarda solunumsal semptomlar alt gruplara ayrilmadan en s1k konsültasyon istenme sebebi solunumsal semptomlar olarak belirtilmiştir (11). Çalışmamızda ikinci en sık konsültasyon istenme sebebi ise genel durum bozukluğudur. Genel durum bozukluğu nedeniyle bu kadar sık konsültasyon istenmesinin sebebi öz bakımını yapamayan hastaların çoğunlukta olması olabilir.

Yaş ile birlikte akciğer enfeksiyonlarının sıklığı artmaktadır. Yaşlılarda gençlere göre pnömoni nedenli hastane yatış oranı yüksektir (12). İlerleyen yaş ile birlikte komorbid durumların artması (KOAH, kardiyovasküler hastalıklar, endokrinolojik hastalıklar, nörolojik hastalıklar), yutma fonksiyonunda bozulma, tekrarlayan aspirasyonlar, kognitif fonksiyonlarda bozulma, yetersiz ve dengesiz beslenme, immünsupresif tedavi gibi çeşitli durumların varlığında pnömoni riski $\operatorname{artar}$ (13-15). Çalışmamızda en sık konsültasyon istenme nedeni ve hastane yatış nedeninin pnömoni olduğunu tespit ettik. Acil servisten pnömoni ön tanısıyla konsülte edilen hastaların büyük çoğunluğu ek hastalığı olan ileri yaş ve bakıma muhtaç hastalardan oluşmaktaydı. $\mathrm{Bu}$ durum pnömoni gelişme riskini arttırmış olabilir.

Kronik akciğer hastalıkları içerisinde en sık konsültasyon istenen hastalık KOAH olarak saptadık. Türkiye'de yapılan birçok çalışmada kronik hastalıklar içerisinde en sık konsültasyon istenen hastalığın KOAH olduğu vurgulanmıştır $(4,7,10,16)$. Bunun nedeninin konsültasyon istenen hastaların önemli bir kısmının yaşlı ve sigara içicisi olduğu belirtilmiştir. Annakkaya ve arkadaşlarının (7) çalışmasında istenen konsültasyonların \%14'ü KOAH, Arslan ve arkadaşlarının çalışmasında ise \%36 olarak tespit edildi. Bizim çalışmamızda acil servisten istenen konsültasyonların \%17,9'u KOAH alevlenme idi. Bir diğer kronik akciğer hastalığı olan astım toplumda \%2-17 arasında görülmektedir (17). Yapılan çalışmalarda göğüs hastalıkları uzmanlarından astım nedeniyle istenen konsültasyonların oranı \%1,4-14,5 arasında değişmektedir $(10,16,18)$. Bizim çalışmamızda da diğer çalışmalara paralel olarak \%13,8 olarak tespit edildi.

Acil serviste hastaların en önemli memnuniyetsizlik nedenlerinden biri hastanın bekleme süresinin uzamasıdır. Etkin bir acil serviste hasta bekleme süresi pek çok faktörden etkilenir; fiziki yapısının yeterliliği, sağlık ekibinin tecrübesi ve takım olabilme becerisi, hemşire ve doktor sayısının yeterliliği, tanısal testlere (laboratuvar, radyoloji) kolay ulaşılabilirlik, kayıt ve iletişim sisteminin kalitesi ve konsültasyon doktorlarına ulaşılabilirlik gibi faktörler bu sürecin belirleyicileridir (2). Acil servislerde endişeli hasta ve yakınları tetkik ve konsültasyonlar nedeni ile tedavinin uzamasını geç müdahale olarak algılayabilir. Bu nedenle de sağlık çalışanı sorumlu tutulabilir ve hasta yakını şiddet eğilimi gösterebilir (2). Çalışmamızda ortalama konsültasyona yanıt verilme süresi 93,8 dakikadır. Türkiye'de yapılan diğer çalışmalardan Dönmez ve arkadaşlarının (3) yaptığı çalışmada cerrahi branşlarda bu süre 124-222 dakika iken, dahili branşlarda 234-306 dakikadır. 2018 yılında yayınlanan yataklı sağlık tesislerinde acil servis hizmetlerinin uygulama ve esasları hakkında tebliğde değişiklik yapılmasında dair tebliğde "konsültasyon bakılma süreleri aciliyetine göre en fazla 30 dakikadır" denilmektedir. Ancak görüldüğü üzere konsültasyonun yanıtlanma süresi istenen süreden çok daha fazla sürmektedir. Bunun çeşitli nedenleri olabilmektedir. Hastanemizde acil servis konsültasyonlarının uzun sürede cevaplanmasının nedenleri; yılın büyük bir bölümünde tek hekim olması, poliklinikte bakılan hasta sayısının yüksek olması ve çevrede il ve ilçelerde göğüs hastalıkları uzmanının olmamasından ötürü oluşan yoğunluk sayılabilir.

Çalışmamızda mevsimsel olarak en fazla konsültasyon istenen mevsim sonbahar idi. Mükerrer başvurularda ilk başvuruyu almamıza rağmen sonbahar aylarında hasta sayısının artması ilginçtir. Olasılıkla havalar nispete daha iyi olduğu yaz mevsiminden havaların bozulmaya başladığı sonbahar mevsimine geçişte hastaların hava koşullarına uygun giyinmemesi pnömoni, KOAH alevlenme gibi hastalıkları artışına sebep olmaktadır. Mevsimsel olarak en fazla mortalitenin kış döneminde olduğunu tespit ettik. Ancak olgu sayılarının az olması sebebiyle istatistiksel anlamlılık bakılmadı.

\section{Kisitlılıklar}

Çalışma dosya taraması şekline yapıldığı için hastaların pnömokok aşısı yapılma durumuna ulaşılamadı. Ayrıca hastaların yaklaşık yarısının sigara kullanma durumlarına ulaşılamadı. Sonuçlar değerlendirilirken bunların göz önünde bulundurulması gerekmektedir.

\section{Sonuç}

Sonuç olarak ikinci basamak devlet hastanesinde acil servisten göğüs hastalıkları branşında istenen konsültasyonların incelendiği bu çalışmada hastaların önemli bir kısmının ileri yaşta olduğu, bakıma muhtaç olduğu gözlemlendi. En sık yatış nedeninin pnömoni olduğu ve bu hastaların önemli bir kısmına kardiyovasküler hastalıkların eşlik ettiği sonucuna varıldı. Ayrıca acilden istenen konsültasyonlara bakılma süresi olması gereken süreden oldukça uzundur.

Acil servis ve göğüs hastalıkları - Üzer ve ark. 


\section{Kaynaklar}

1.Şahinoğlu-Pelin S, Çalişir HC. Tıpta Konsültasyon Atatürk Göğüs Hastalıkları ve Göğüs Cerrahisi Merkezi’ndeki 81 Hekimin Konsültasyonla İlgili Görüşleri Özelinde. Turkiye Klinikleri J Med Ethics. 1998;6(1):14-19.

2.Özyurt E, Aykutluğ M, Uğurlu D, et al. Acil servis konsültasyon sürecinde SMS uygulaması Dışkapı Hastanesi modeli. Sağlık Akademisyenleri Dergisi. 2018;5(4):275281. doi:10.5455/sad.13-1529306047

3.Dönmez SS, Durak VA, Torun G, Köksal Ö, Aydin Ş. Acil Serviste Gerçekleştirilen Konsültasyon Sürecinin İncelenmesi. Uludağ Üniversitesi Tip Fakültesi Dergisi. 2017;43(1):23-28.

4.Arslan S, Berk S, Bulut G, Karşikaya H, Akkurt İ. Üniversite hastanesinde yatağında istenen gögüs hastalıkları konsültasyonlarının değerlendirilmesi. Cumhuriyet Tıp Dergisi. 2010;32(2):199-204.

5.Karnak D, Köksal D, Moğulkoç G, Beder S, Pınar E. Göğüs Hastalıkları Konsültasyonı Yapılan Olguların Değerlendirilmesi. Tüberküloz ve Toraks. 2002;50(4):462-8

6.Aşker UDM, Timuçin UDÖB, Aşker UDS. Bir Kalp Hastanesinde Göğüs Hastalıkları Konsültasyonu Yapılan Olguların Değerlendirmesi. Turkiye Klinikleri Arch Lung. 2012;13(1):1-5.

7.Annakaya AN, Tozkoparan E, Deniz Ö, Özkan M, Bilgiç H, Ekiz K. Yatağında göğüs hastalıkları konsültasyonu. Gülhane Tıp Dergisi 2005; 47: 6 - 10

8.Uluorman F, Dallı A, Ayık Öktem S, Coşkunol İ, Kaçar ZC, Alp Aİ et al. Göğüs hastalıkları pre-operatif konsültasyonu yapılan hastaların değerlendirilmesi. İzmir Göğüs Hastanesi Dergisi. 2015;26(3):139-143.

9.Cakmak G, Saglam ZA. Evaluation of Chest Disease Consultations. Global Journal of Medical research Diseases. 2013;13(4).1-4.

10.Öztürk Ö, Ünlü A, Bircan H, Şahin Ü, Akkaya A. Göğüs hastalıkları konsültasyonu yapılan olguların değerlendirilmesi. SDÜ Tıp Fakültesi Dergisi; 2005;12(1):27-31

11.Güleç Balbay E. Devlet Hastanesinde Yatağında İstenen Göğüs Hastalıkları Konsültasyonları. Konuralp Tıp Dergisi. 2013;5(1):34-37.

12.Gavazzi G, Krause K-H. Ageing and infection. Lancet Infect Dis. 2002;2(11):659-666. doi:10.1016/s1473-3099(02)00437-1

13.Çakmak ME. Göğüs hastalıkları servisimizde izlenen 85 yaş ve üzeri geriatrik hastaların değerlendirilmesi. İzmir Göğüs Hastanesi Dergisi. 2016;30(3):167-172.

14.Loeb M, McGeer A, McArthur M, Walter S, Simor AE. Risk factors for pneumonia and other lower respiratory tract infections in elderly residents of long-term care facilities. Arch Intern Med. 1999;159(17):2058-2064. doi:10.1001/archinte.159.17.2058

15.Ruiz M, Ewig S, Marcos MA, et al. Etiology of community-acquired pneumonia: impact of age, comorbidity, and severity. Am J Respir Crit Care Med. 1999;160(2):397405. doi:10.1164/ajrccm.160.2.9808045

16.Emre JÇ, Baysak A, Özdemir Ö, Aksoy Ü, Dirican N, Öz AT. The Evaluation of Pulmonology Consultation Requests in a State Hospital. J Clin Anal Med 2015;6(4): 443-

17.Türk toraks derneği astım allerji çalışma grubu yürütme kurulu. Türk toraks derneği astım tanı ve tedavi rehberi. Turkish Thoracic Journal. 2016: (Suppl 1).

18.Kalkantzi A, Filippidou E-C, Liolios E, et al. 009. Evaluation of respiratory symptoms in the emergency department. J Thorac Dis. 2015;7(Suppl 1). doi:10.3978/j.issn.20721439.2015.AB009

Acil servis ve göğüs hastalıkları - Üzer ve ark. 